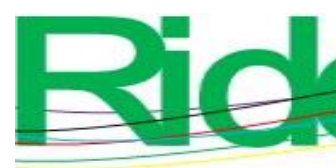

\title{
Evaluación del impacto de la infraestructura física educativa en la educación
}

\author{
Evaluation of the impact of the Physical Educational Infrastructure in \\ education
}

\section{Avaliação do impacto da infraestrutura física educacional na educação}

\author{
Nancy Jacqueline Pacheco Martínez \\ Centro de Estudios e Investigaciones para el Desarrollo Docente A. C., México \\ nancyv9@yahoo.com.mx \\ https://orcid.org/0000-0001-8621-8921
}

\section{Resumen}

Esta investigación tuvo como objetivo evaluar las condiciones y el estado actual de la infraestructura física educativa (INFE) y su efecto en la educación a nivel preescolar. Para ello, se concretó un estudio de caso en el que se incluyeron los jardines de niños públicos ubicados en la región central de la República mexicana. Las preguntas formuladas fueron las siguientes: ¿qué relación existe entre la INFE y la educación que en su interior se imparte?, ¿cuánto impacta el estado actual de la INFE en la eficacia de la educación? y ¿qué papel desempeña el cumplimiento normativo de la INFE en dicha relación e impacto en la educación? El estudio desarrollado fue de tipo mixto, ya que se utilizaron técnicas cuantitativas, cualitativas y de carácter multidisplinario. Los instrumentos utilizados fueron la selección de la muestra representativa a través de un proceso aleatorio, la observación no participativa, el levantamiento físico de datos, el soporte fotográfico y el análisis de cumplimiento normativo con base en lo que señalan la Ley General de Educación (LGE, 2019), los reglamentos de construcciones de cada uno de los estados evaluados, las normas oficiales mexicanas de tipo obligatorio y de observancia voluntaria, así como los lineamientos de la Secretaría de Educación Pública (SEP,1921), Manuales de Protección 


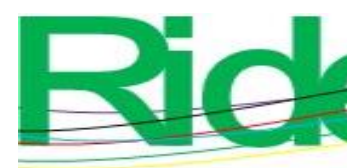

Revista Iberoamericana para la
Investigación y el Desarrollo Educativo
ISSN $2007-7467$

Civil e informes de la Organización para la Organización para la Cooperación y el Desarrollo Económicos (OCDE, 1961).Los resultados indican que el estado físico y el emplazamiento de los centros educativos inciden directamente en el desempeño de los estudiantes, por lo que se debe gestionar la adecuada supervisión por parte de las autoridades y de los mismos usuarios (docentes, administrativos y personal), quienes deben identificar los riesgos y las condiciones en las que se prestan los servicios de educación a nivel de preescolar en México. Asimismo, se debe fomentar la mejora continua de la calidad de la INFE para consolidar el derecho a la educación de todos los niños y las niñas de este país.

Palabras clave: Infraestructura Física Educativa, impacto, nivel de enseñanza y plantel educativo.

\section{Abstract}

This research aimed to evaluate the conditions and current state of the educational physical infrastructure (INFE) and its effect on education at the preschool level. For this, a case study was carried out that included public kindergartens located in the central region of the Mexican Republic. The questions asked were the following: what is the relationship between INFE and the education that is taught within it? How much does the current state of INFE impact on the effectiveness of education? And what role does INFE regulatory compliance play in this relationship and impact on education? The study developed was of a mixed type, since quantitative, qualitative and multidisciplinary techniques were used. The instruments used were the selection of the representative sample through a random process, nonparticipatory observation, physical data collection, photographic support and analysis of regulatory compliance based on what the General Education Law (LGE, 2019), the construction regulations of each of the evaluated states, the official Mexican standards of mandatory and voluntary observance, as well as the guidelines of the Ministry of Public Education (SEP, 1921), Civil Protection Manuals and reports from the Organization for Economic Cooperation and Development (OECD, 1961). The results indicate that the physical condition and location of educational centers have a direct impact on student performance, so the adequate supervision by the authorities and the users themselves (teachers, administrators and staff), who must identify the risks and conditions in which education services are provided at the preschool level in Mexico. Likewise, the continuous 


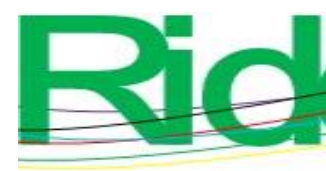

Revista Iberoamericana para la Investigación y el Desarrollo Educativo ISSN $2007-7467$

improvement of the quality of the INFE should be promoted to consolidate the right to education of all boys and girls in this country.

Keywords: Physical Educational Infrastructure, impact, teaching level and Educational Campus.

\section{Resumo}

Esta pesquisa teve como objetivo avaliar as condições e o estado atual da infraestrutura física educacional (INFE) e seus efeitos na educação em nível pré-escolar. Para isso, foi realizado um estudo de caso que incluiu creches públicas localizadas na região central da República Mexicana. As perguntas feitas foram as seguintes: qual a relação existente entre o INFE e a educação que é ministrada nele? Quanto o estado atual do INFE impacta na eficácia da educação? E que papel a conformidade regulatória do INFE desempenha nessa relação e impacto na educação? O estudo desenvolvido foi do tipo misto, uma vez que foram utilizadas técnicas quantitativas, qualitativas e multidisciplinares. Os instrumentos utilizados foram a seleção da amostra representativa por meio de processo aleatório, observação não participativa, coleta de dados físicos, suporte fotográfico e análise do cumprimento regulatório com base no que dispõe a Lei Geral de Educação (LGE, 2019), o regulamento de construção. de cada um dos estados avaliados, as normas mexicanas oficiais de observância obrigatória e voluntária, bem como as diretrizes do Ministério da Educação Pública (SEP, 1921), Manuais de Proteção Civil e relatórios da Organização para a Organização para a Cooperação Econômica e Desenvolvimento (OCDE, 1961). Os resultados indicam que a condição física e a localização dos centros educacionais têm impacto direto no desempenho dos alunos, por isso a adequada supervisão por parte das autoridades e dos próprios usuários (professores, administradores e funcionários), quem deve identificar o riscos e condições em que os serviços de educação são prestados no nível pré-escolar no México. Da mesma forma, deve-se promover a melhoria contínua da qualidade do INFE para consolidar o direito à educação de todos os meninos e meninas deste país.

Palavras-chave: Infraestrutura Física Educacional, impacto, nível de ensino e estabelecimento educacional.

Fecha Recepción: Noviembre 2020

Fecha Aceptación: Mayo 2021 


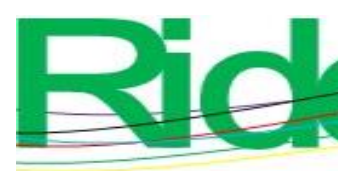

Revista Iberoamericana para la
Investigación y el Desarrollo Educativo
ISSN $2007-7467$

físicas de las escuelas y el rendimiento de los estudiantes a nivel de escuela intermedia en el estado de Virginia.

Asimismo, Boese y Shaw (2005) señalan que el estado de las instalaciones escolares de New York repercute en la salud y el rendimiento de los escolares, de ahí que abogue por escuelas saludables para los educandos. Picus, Marion, Calvo y Glenn (2005) enseñan el vínculo entre el rendimiento estudiantil y la calidad de las instalaciones educativas. Higgins, Hall, Wall, Woolner y McCaughey (2005) se refieren a las campañas de quienes participan en el liderazgo, el diseño, la planificación, la dotación de recursos y la gestión de las escuelas británicas, mientras que Branham (2004) afirma que la calidad de la infraestructura escolar tiene un efecto significativo en las tasas de asistencia y deserción escolar.

Por todo lo anterior, resulta relevante la información presentada en este artículo sobre las condiciones en las que se encuentran los planteles educativos a nivel preescolar, específicamente en la región central de la República mexicana. Para ello, se tratan temas vinculados con el número de alumnos y de maestros en los salones de clase, el mobiliario y el equipo, el mantenimiento, los servicios municipales, las instalaciones (eléctricas e hidrosanitarias), el medio ambiente y la seguridad, entre otros.

En tal sentido, las preguntas formuladas fueron las siguientes:

- ¿Qué relación existe entre la INFE y la educación que en su interior se imparte?

- ¿Cuánto impacta el estado actual de la INFE en la eficacia de la educación?

- ¿Qué papel desempeña el cumplimiento normativo de la INFE en dicha relación e impacto en la educación?

\section{Marco metodológico}

La presente investigación fue mixta, ya que se utilizaron técnicas tanto cuantitativas como cualitativas con un soporte multidisciplinario. El enfoque cuantitativo se empleó al dar a conocer la representación de una realidad concreta y específica, mientras que el paradigma cualitativo se utilizó al recabar la información basada en la observación (soporte fotográfico). Asimismo, fue una investigación multidisciplinaria porque para realizar el análisis del cumplimiento normativo se usaron conocimientos de ingeniería civil, análisis de espacios arquitectónicos, seguridad estructural y principios básicos de derecho. 


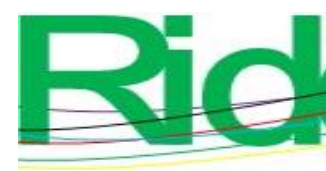

Revista Iberoamericana para la
Investigación y el Desarrollo Educativo ISSN 2007-7467

\section{Datos}

Población: Ubicada en la región central de la República mexicana.

Muestra: El estudio se llevó a cabo en 18 instituciones educativas de nivel preescolar ubicadas en Ciudad de México (CDMX), estado de México (EDO MÉX), Hidalgo (HGO), Querétaro (QRO), Morelos (MOR) y Tlaxcala (TLAX).

Glosario de términos y/o abreviaturas

DOF: Diario Oficial de la Federación.

CCT: (Clave de Centro de Trabajo): Es la llave de entrada al catálogo de centros de trabajo (escuelas) autorizados por la SEP; además, es el elemento de relación con todos los sistemas de la SEP o de las autoridades educativas en los estados.

Entidad federativa o estado: Unidad delimitada territorialmente que en unión de otras entidades conforman a una nación.

INEE: Instituto Nacional para la Evaluación de la Educación. Tiene como tarea principal evaluar la calidad, el desempeño y los resultados del sistema educativo nacional (SEN) en la educación básica y media superior, de conformidad con el artículo 3 de la Constitución Política de los Estados Unidos Mexicanos (CPEUM, 1917).

Instituto o INIFED: Instituto Nacional de la Infraestructura Física Educativa. Emite normas y especificaciones técnicas, participa en la elaboración de normas mexicanas y elabora guías operativas para la administración de los recursos destinados a la infraestructura educativa. INFE o Infraestructura Física Educativa: Los muebles e inmuebles destinados a la educación impartida por el Estado y los particulares, con autorización o con reconocimiento de validez oficial de estudios, en el marco del sistema educativo nacional, en términos de la Ley General de Educación (DOF, 2019b), así como a los servicios e instalaciones necesarios para su correcta operación.

NOM: Norma Oficial Mexicana de uso obligatorio.

NMX: Normatividad de observancia voluntaria; sin embargo, si son mencionadas como parte de una NOM, su observancia se hace obligatoria.

Plantel: Centro educativo donde se imparte la enseñanza al alumnado.

SEN: Sistema Educativo Nacional. Es el conjunto organizado de servicios y acciones educativas reguladas por el Estado que posibilitan el ejercicio del derecho a la educación. 


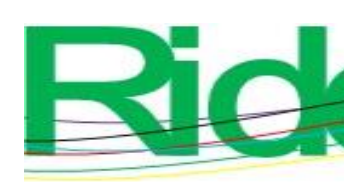

Revista Iberoamericana para la
Investigación y el Desarrollo Educativo
ISSN $2007-7467$

- Apéndice A (normativo), cédula de información técnica (CIT)

- Apéndice B (informativo), guía para el llenado de la cédula de información técnica,

- Apéndice C (normativo), cédula técnica del Centro Nacional de Prevención de Desastres (CENAPRED)

- Apéndice D (normativo), cédula técnica del Instituto Local de la Infraestructura Física Educativa del Distrito Federal (ILIFEDF), todos de la Norma Mexicana NMX-R-084SCFI-2015: Escuelas -levantamiento de datos para el diagnóstico de la infraestructura física educativa - directrices y requisitos.

Asimismo, se realizó un cuestionario formulado con base en el anexo 1 - Formato de Información Técnica para la Evaluación para la Certificación de la Calidad de la INFE (2019) del Instituto de la Infraestructura Física Educativa (INIFED, 2019, en el cual se contemplan los aspectos a evaluar durante la visita, tales como INFE esencial (cuenta con locales mínimos para las actividades curriculares e instalaciones básicas), INFE funcional (cubre con los aspectos del tipo esencial y equipamiento según los avances pedagógicos y tecnológicos) e INFE sustentable (cumple aspectos del tipo funcional e incorpora programas de conservación del medio ambiente), así como tipo de espacios educativo, equipos de seguridad y análisis de riesgos.

\section{Etapa II}

En esta etapa se describe el proceso de evaluación de la calidad de la INFE evaluada:

1. Se utilizaron los lineamientos para la formulación de indicadores de la SEP (2019).

2. Ley General de la Infraestructura Física Educativa (LGINFE, 2008).

3. Se analizó cada uno de los aspectos de los centros educativos utilizando la siguiente normatividad:

- NMX-R-083-SCFI-2019. Escuelas — diseño y fabricación de mobiliario para la infraestructura física educativa - criterios y requisitos. Norma Mexicana (2019).

- NMX-R-090-SCFI-2016. Escuelas —elementos para la accesibilidad a los espacios de la infraestructura física educativa - requisitos. Norma Mexicana (2016). 


\section{Revista Iberoamericana para la Investigación y el Desarrollo Educativo ISSN 2007 - 7467}

- NMX-R-084-SCFI-2015 Escuelas - levantamiento de datos para el diagnóstico de la infraestructura física educativa — directrices y requisitos. Norma Mexicana (2015a).

- NMX-R-024-SCFI-2015. Escuelas — supervisión de obra de la infraestructura física educativa - requisitos. Norma Mexicana (2015b).

- NMX-R-079-SCFI-2015 Escuelas — seguridad estructural de la infraestructura física educativa - requisitos. Norma Mexicana (2015c).

- NMX-R-080-SCFI-2015 Escuelas — bebederos de agua potable- requisitos. Norma Mexicana (2015d).

- NMX-R-021-SCFI-2013 Escuelas —calidad de la infraestructura física educativa- requisitos. Norma Mexicana (2013).

- NMX-R-003-SCFI-2011. Escuelas —selección del terreno para construcciónrequisitos (cancela a la NMX-R-003-SCFI-2004). Norma Mexicana (2011).

4. Referente a la suficiencia básica y necesaria para impartir clases, se analizó que las escuelas cumplieran con los conceptos de la Organización para la Cooperación y el Desarrollo Económicos (OCDE), que son los siguientes:

- Uso comunitario: i) Accesibilidad a la comunidad para utilizar las instalaciones durante o después del horario escolar.

- Ambiente sustentable: i) Planeación del sitio: El espacio demuestra planeación del sitio ambiente sustentable. ii) Sistemas sustentables: Demuestra uso efectivo y eficiente de agua, energía, reciclaje, disposición de basura, luz natural. iii) El espacio demuestra el uso de métodos constructivos, materiales constructivos.

- Participación social: i) Mantenimiento: Evidencia de la participación constante de la comunidad educativa en el mantenimiento preventivo que no requieren mano de obra especializada de los edificios, instalaciones y equipos de los planteles educativos.

5. La información fue respaldada a través de reportes fotográficos.

6. Se consultaron los reglamentos de construcción y de Protección Civil por cada estado evaluado.

Para el análisis de evidencia de afectación sobre el aprendizaje se consideraron algunos de los siguientes factores (tabla 2): 
Tabla 2. Factores que impactan en el aprendizaje

\begin{tabular}{|c|c|}
\hline Factor & Variables consideradas \\
\hline Pedagógicos & $\begin{array}{l}\text { Número de alumnos por maestro. } \\
\text { Métodos y materiales didácticos utilizados. } \\
\text { Tiempo dedicado por los profesores a la preparación de sus clases. } \\
\text { Mobiliario y equipo. } \\
\text { Condiciones del inmueble. } \\
\text { Edad del inmueble. } \\
\text { Mantenimiento de las instalaciones. } \\
\text { Instalaciones. } \\
\text { Servicios municipales. }\end{array}$ \\
\hline Psicológicos & $\begin{array}{l}\text { Trastornos o desórdenes de interiorización. } \\
\text { Sobre control o ansiedad/retraimiento. } \\
\text { Conductas como ansiedad, timidez, retraimiento y depresión de la } \\
\text { percepción. } \\
\text { Memoria y conceptualización que dificultan el aprendizaje. }\end{array}$ \\
\hline Factor & Variables consideradas \\
\hline Sociológicos & $\begin{array}{l}\text { Características familiares y socioeconómicas de los estudiantes. } \\
\text { Nivel de escolaridad. } \\
\text { Calidad del medio ambiente que rodea al estudiante. } \\
\text { Seguridad (protección civil). }\end{array}$ \\
\hline Fisiológicos & $\begin{array}{l}\text { Hormonales } \\
\text { Problemas de salud (deficiencias en los órganos de los sentidos) } \\
\text { Desnutrición y problemas de peso y salud. }\end{array}$ \\
\hline
\end{tabular}

Fuente: Elaboración propia con base en Durón y Oropeza (1999), Jenkins y Oatley (1998) y Mahoney (1997) 


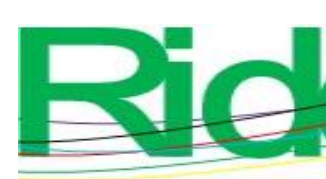

Revista Iberoamericana para la Investigación y el Desarrollo Educativo ISSN $2007-7467$

\section{Resultados}

A partir de los datos obtenidos en las etapas I y II del estudio, la figura 1 enseña que la Ciudad de México es la única entidad en la cual se cumple, en promedio, con $74 \%$ del uso específico del inmueble como edificio educativo, aunque solo con $6.4 \%$ según los conceptos de la OCDE, que se refieren a la suficiencia básica y necesaria del inmueble para poder impartir clases. Es decir, ningún inmueble evaluado en las otras entidades logró su cumplimiento y solo en el estado de Morelos se obtuvo el mayor valor con $20.6 \%$. Cabe señalar que la LGE establece (en su artículo 99) que los muebles e inmuebles deberán cumplir con los requisitos de "calidad, seguridad, funcionalidad, oportunidad, equidad, sustentabilidad, resiliencia, pertinencia, integridad, accesibilidad, inclusividad e higiene". Por ello, para su evaluación en este ámbito se definieron tres dimensiones prioritarias, las cuales cada escuela debe cumplir como parte esencial del derecho a la educación: servicios básicos en el plantel, espacios escolares suficientes y accesibles, y condiciones básicas de seguridad e higiene. Sin embargo, como se aprecia en la figura 1, resultó nulo su cumplimiento y ningún plantel evaluado en este rublo llegó a la media promedio.

Figura 1. Porcentaje de cumplimiento normativo del inmueble como espacio educativo según los conceptos que señala la OCDE

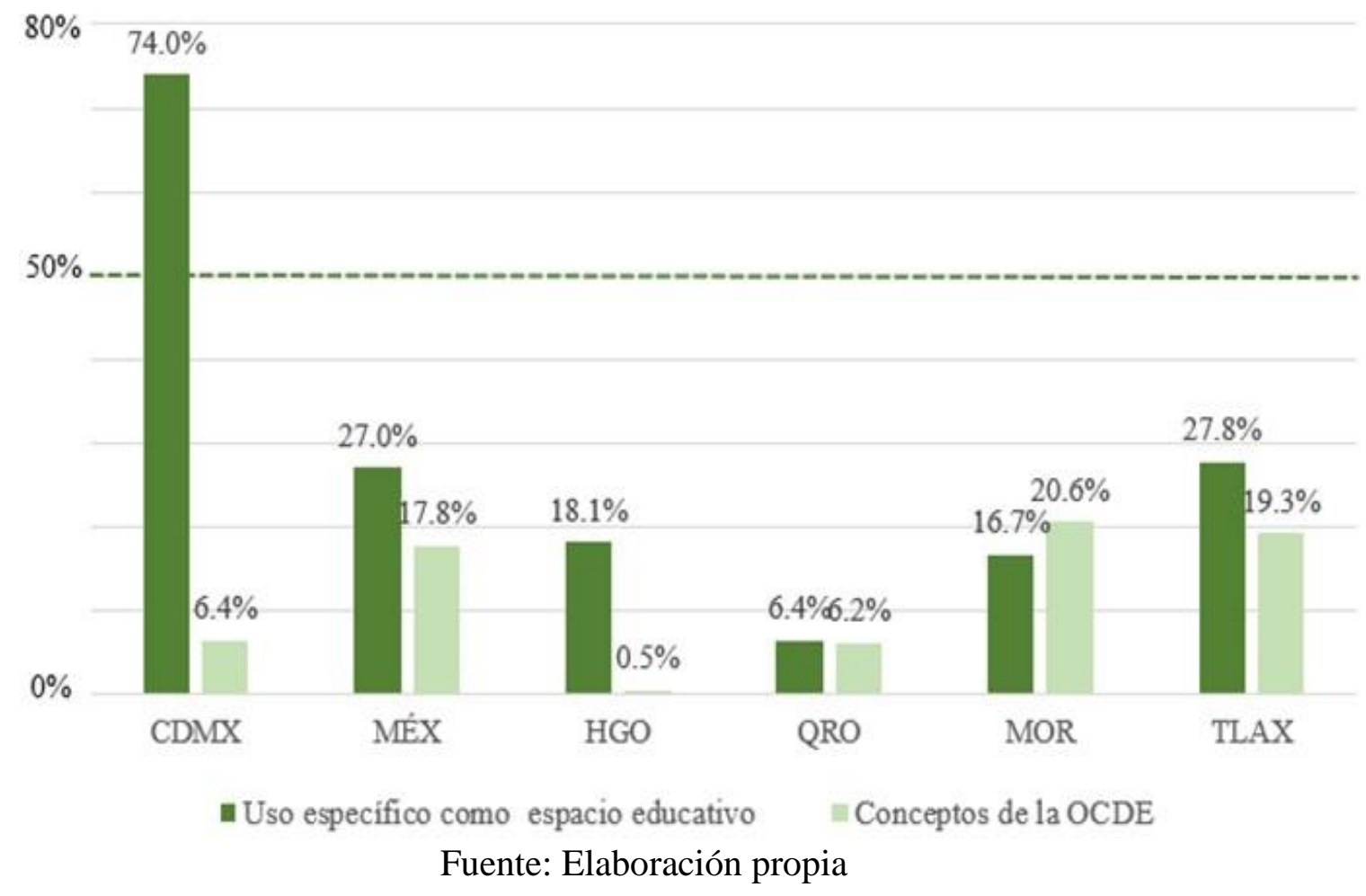




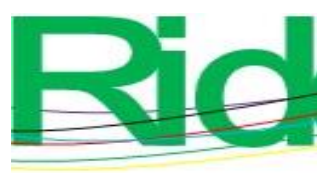

Revista Iberoamericana para la Investigación y el Desarrollo Educativo ISSN $2007-7467$

La tabla 3 revela los datos obtenidos en porcentajes de los planteles evaluados por estados.

Tabla 3. Evaluación de la INFE

\begin{tabular}{|l|c|c|c|c|c|}
\hline \multicolumn{1}{|c|}{ Entidad } & $\begin{array}{c}\text { Edad del } \\
\text { inmuebl } \\
\text { e (años) }\end{array}$ & Planeación general & $\begin{array}{c}\text { Proyecto } \\
\text { ejecutivo }\end{array}$ & $\begin{array}{c}\text { Mobiliario } \\
\text { y equipo }\end{array}$ & $\begin{array}{c}\text { Mantenimien } \\
\text { to }\end{array}$ \\
\hline CDMX & 45 & 25.6 & 12.8 & 15.5 & 5.11 \\
\hline EDO MÉX & 48 & 23.0 & 19.4 & 37.5 & 10.4 \\
\hline HGO & 44 & 10.1 & 8.6 & 1.73 & 1.6 \\
\hline QRO & 50 & 14.1 & 19.4 & 18.8 & 1.2 \\
\hline MOR & 45 & 23.8 & 54.1 & 46.0 & 2.2 \\
\hline TLAX & 43 & 31.0 & 51.7 & 59.8 & 2.2 \\
\hline
\end{tabular}

Fuente: Elaboración propia

En la tabla anterior se aprecia que la infraestructura escolar carece de cumplimiento en rubros específicos básicos, los cuales se detallan a continuación:

La planeación general de las construcciones escolares, en la cual se tiene que tomar en consideración, entre otros aspectos, la demanda escolar, la capacidad instalada, la zona de influencia, la consolidación, el nuevo edificio, la reparación, la modalidad de los diferentes niveles educativos y la selección de terreno. Lo anterior repercute significativamente en la educación de los alumnos, ya que no cuentan con una INFE planeada inicialmente para tal fin.

En cuanto al proyecto ejecutivo de las escuelas, este deberá ser la representación o expresión gráfica de la solución a los requerimientos proporcionados por el área encargada de la planeación educativa de la SEP y, en su caso, constará de los planos siguientes: planta de conjunto o plan maestro, plantas generales de los edificios, fachadas y cortes generales, planos de modificaciones y de todas las instalaciones. No obstante, los resultados indican que solo los estados de Morelos y Tlaxcala alcanzaron $54.1 \%$ y $51.6 \%$ de cumplimiento normativo, respectivamente, lo que nos llevó a plantearnos la siguiente interrogante: ¿el plantel se diseñó originalmente para tal fin o fue adaptado?, ya que ninguno presentó evidencia alguna sobre su planeación, diseño, etc. Aunado a ello, se registraron algunos casos donde se efectuaron diversas intervenciones a las instalaciones sin contar con algún proyecto o registro de ello. 


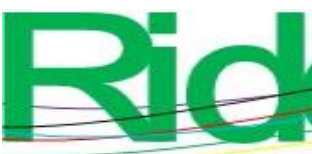

Lo anterior impacta en el aprendizaje de los estudiantes debido a que pasan muchas horas en un lugar que no cuenta con las condiciones básicas para tal fin. Como soporte de lo antes mencionado, se muestran las figuras 2 y 3 .

Figura 2. Evidencia de construcciones con diseño habitacional que funcionan como planteles educativos (jardín de niños)
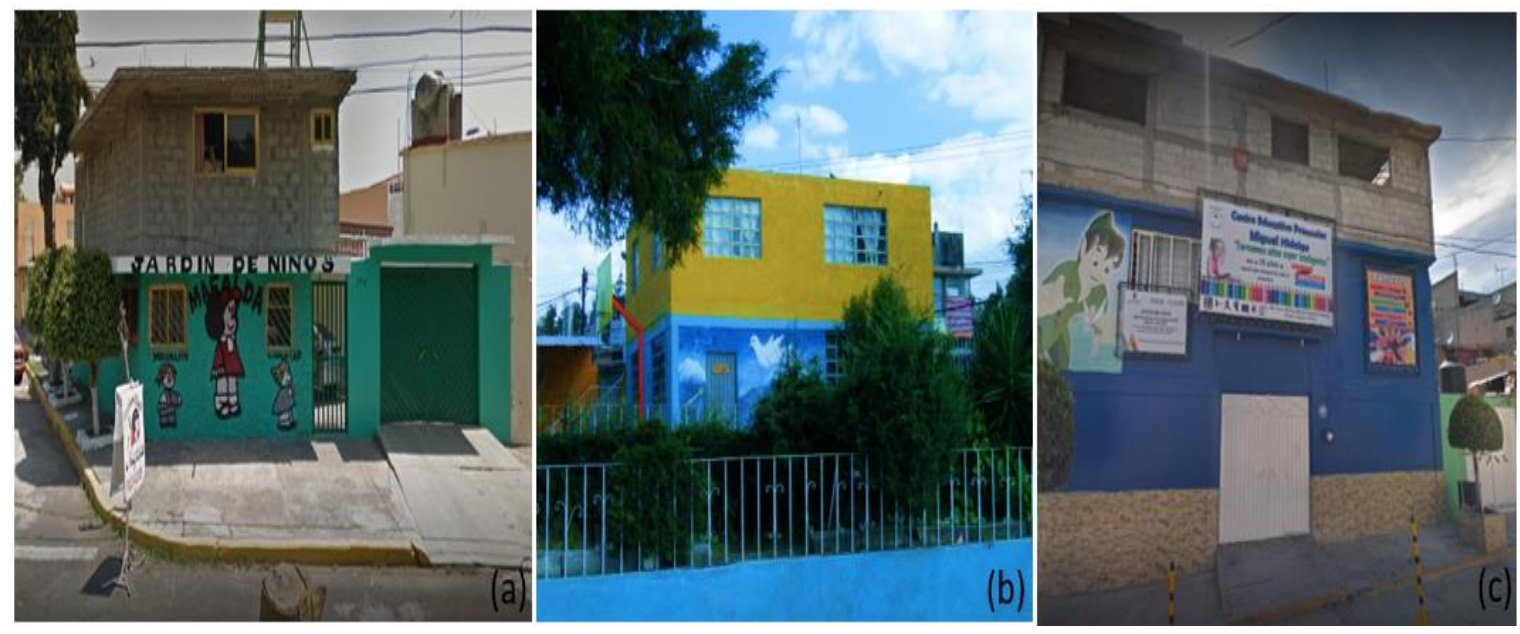

Fuente: Fotografía de Nancy Pacheco. (a) Estado de Tlaxcala de Xicoténcatl (2018), (b)

Estado de Querétaro, municipio Arroyo Seco (2018) y (c) Ciudad de México, municipio

Miguel Hidalgo (2018).

Figura 3. Evidencia de construcciones de espacios exteriores inadecuados para operar como escuelas, con cuartos construidos como anexos y fuera de la norma, así como inadecuada planeación de las aulas y de acceso a ellas
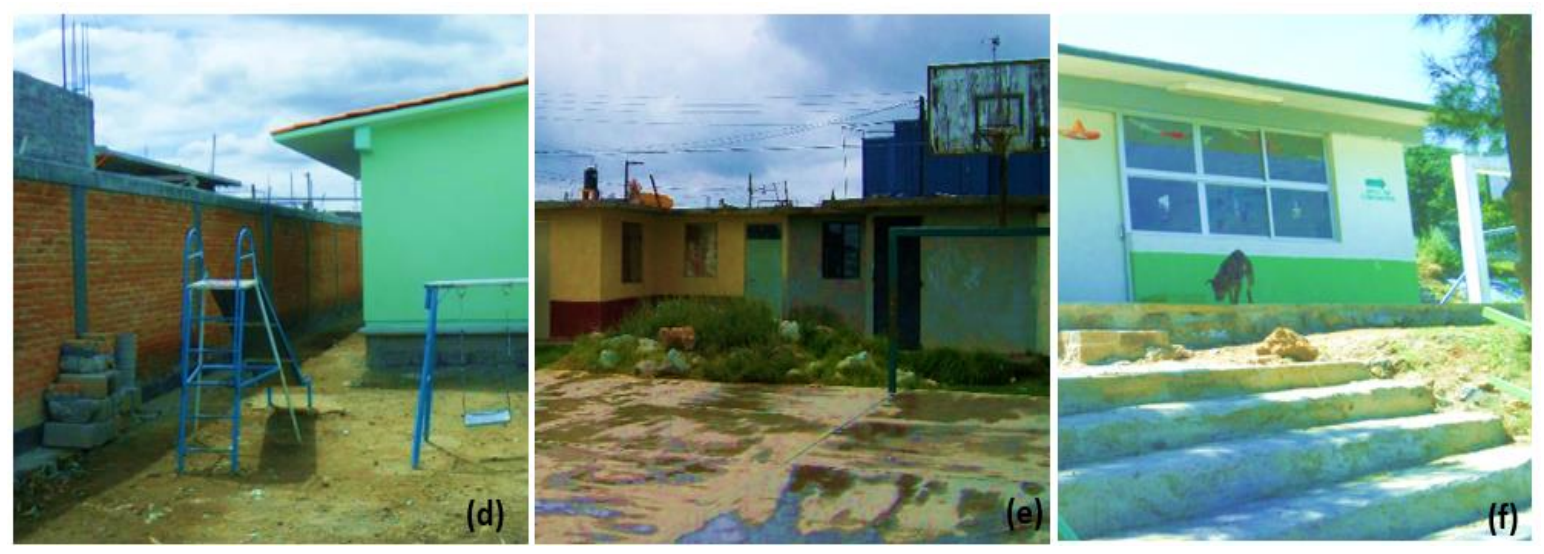

Fuente: Fotografía de Nancy Pacheco. (d) Estado de Hidalgo Pachuca del Soto (2019), (e)

Estado de Morelos, municipio de Cuautla (2019) y (f) Estado de México, municipio de Valle de Cahalco (2019) 

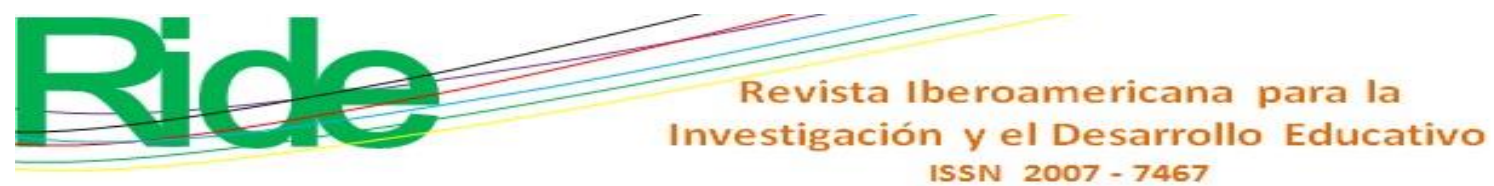

ISSN 2007 - 7467

Asimismo, en lo concerniente al mobiliario y equipo como medio didáctico para el proceso de enseñanza-aprendizaje, este requiere de características particulares determinadas por el nivel educativo, el uso (calidad, materiales, durabilidad, etc.), los requerimientos pedagógicos y ergonómicos, así como por el tipo y características del espacio amueblado, ya que se considera que el mobiliario escolar será usado por cientos de estudiantes durante un largo periodo. Por eso, se debe procurar su calidad para que tenga una adecuada duración y sean seguros. Igualmente, en la evaluación se consideró que el mobiliario debe ser elegido según la edad de los alumnos, el tamaño de las aulas y el número de estudiantes, ya que es importante que los niños y niñas se encuentren en un ambiente adaptado a sus medidas corporales (ergometría y discapacidades) (figura 4).

Figura 4. Mobiliario fuera de la norma para el nivel escolar, con material frágil, nulo mantenimiento y cantidad de mobiliario inadecuado
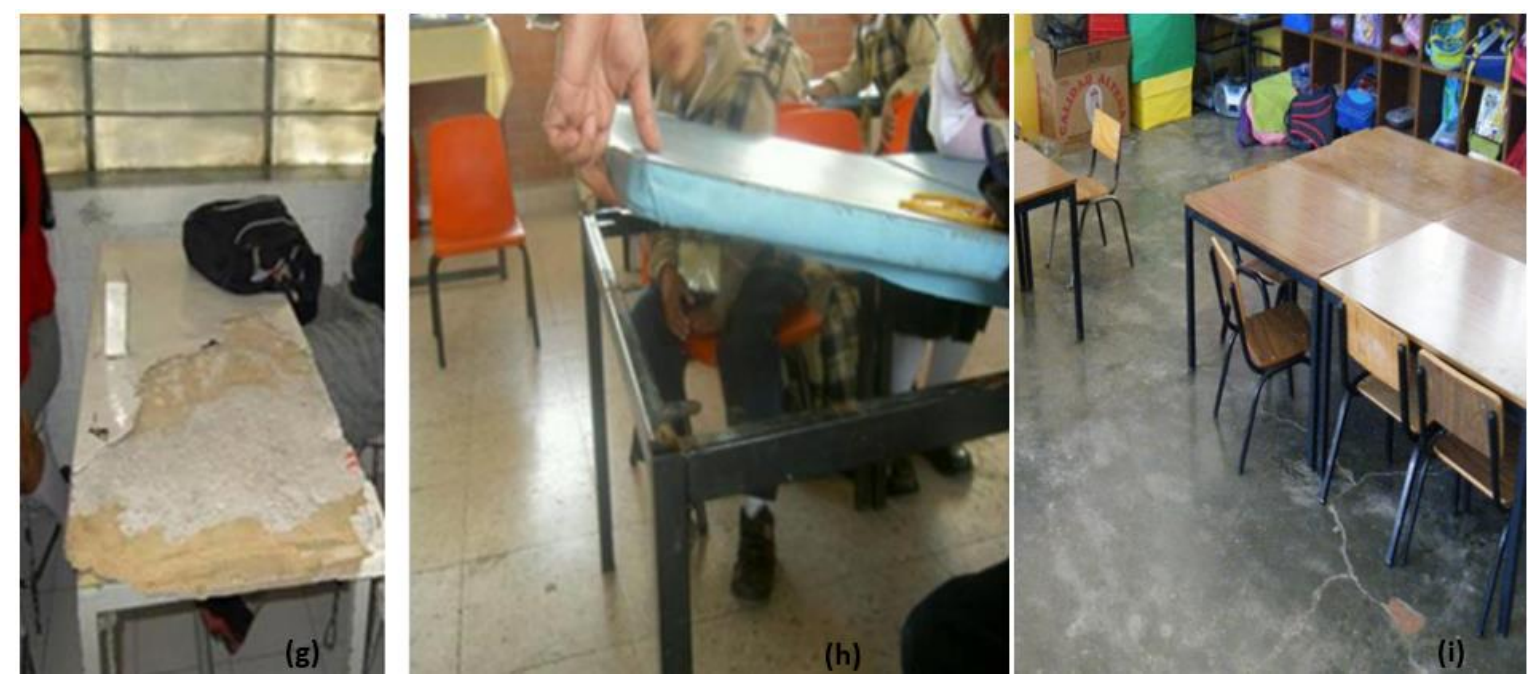

Fuente: Fotografía de Nancy Pacheco. (g) Estado de Hidalgo, municipio de Atapexco (2019), (h) Ciudad de México, municipio de Xochimilco (2019), (i) Estado de México, municipio de Ecatepec (2019)

De los resultados obtenidos se destaca que de los 18 planteles evaluados solo el estado de Tlaxcala presentó el valor más alto, con $59.8 \%$ de grado de cumplimiento normativo. De hecho, los principales problemas en este rubro fueron los siguientes: mobiliario inadecuado para el nivel educativo, mobiliario requerido de baja calidad e insuficiente y no apto para personas con capacidades diferentes, lo que dificulta el desarrollo óptimo de la labor docente. 

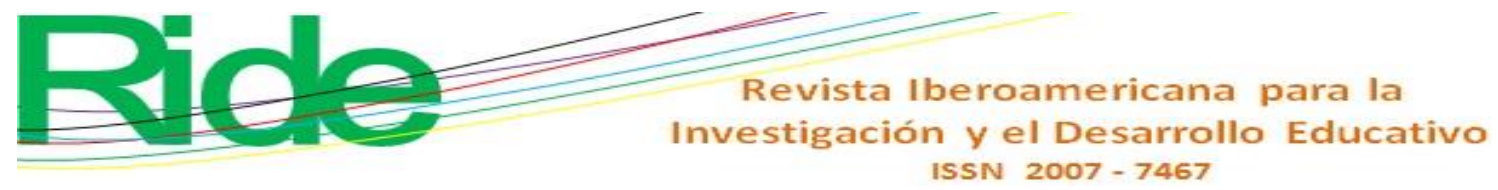

En lo concerniente al mantenimiento, los resultados demostraron que ningún plantel cumplió normativamente y que los valores más altos se consiguieron, en promedio, en el Estado de México y en la Ciudad de México con $10.4 \%$ y $5.11 \%$, respectivamente. Estas cifras resultan preocupantes porque el mantenimiento de las instalaciones y de los materiales usados resulta esencial para evitar accidentes (figura 5).

Figura 5. Áreas de casas adaptadas para funcionar como espacios educativos, carentes de cumplimiento normativo en iluminación, ventilación, mobiliario y áreas comunes para impartir clases a nivel de educación preescolar
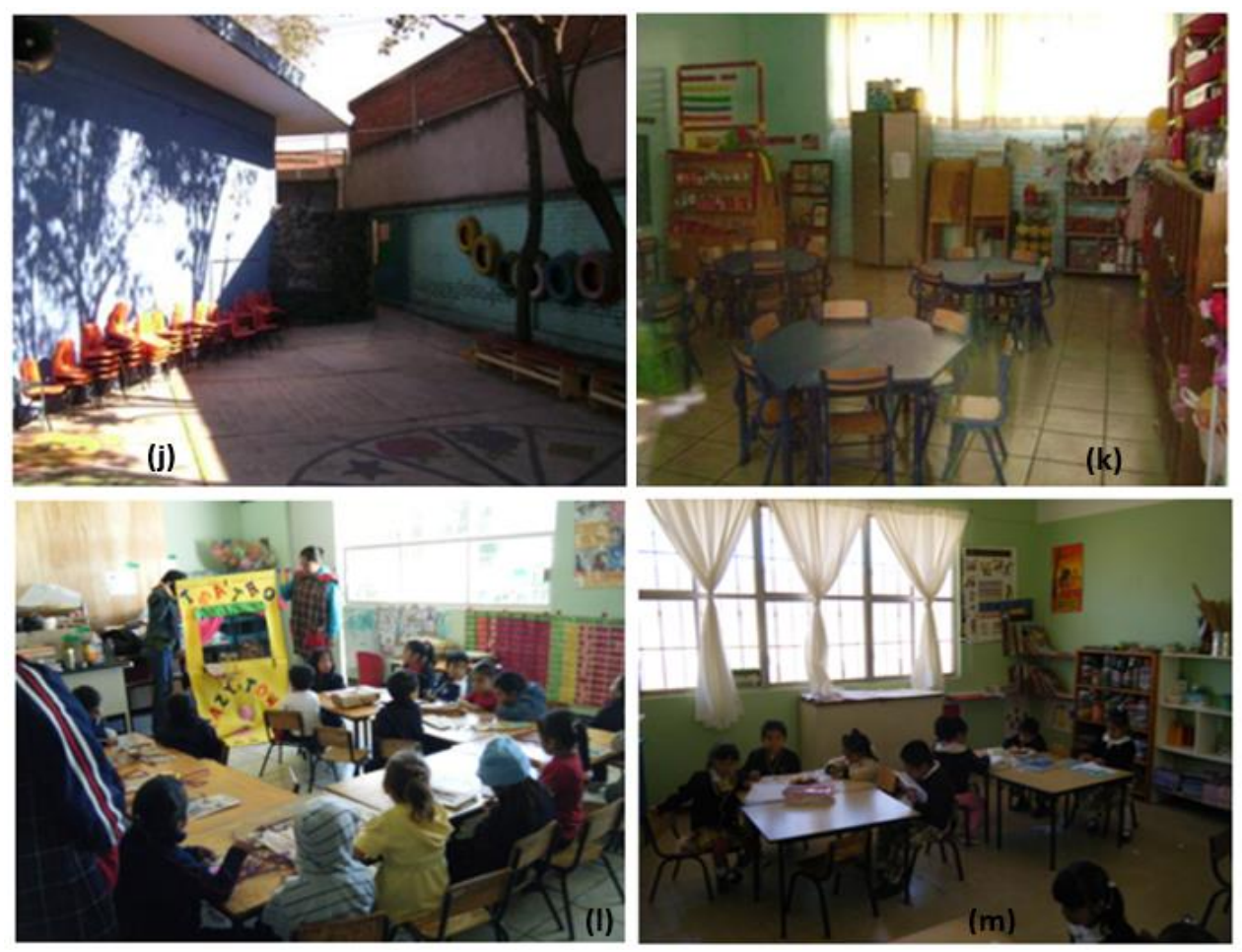

Fuente: Fotografía de Nancy Pacheco. (j) Estado de Querétaro, municipio de Tolimán (2018), (k) Estado de Morelos, municipio de Yautepec (2019), (1) Estado de Tlaxcala, municipio Zacatelco (2019), (m) Estado de Hidalgo, Tolcayuca (2018).

Como se señaló inicialmente, se analizó la INFE tomando en cuenta algunos factores que pueden afectar el normal desarrollo del proceso de enseñanza-aprendizaje, los cuales se muestran en la tabla 4. 


\section{Revista Iberoamericana para la Investigación y el Desarrollo Educativo ISSN 2007 - 7467}

Tabla 4. Estado de la INFE

\begin{tabular}{|l|c|c|c|c|c|c|c|}
\hline \multicolumn{1}{|c|}{ Entidad } & $\begin{array}{c}\text { Servicios } \\
\text { municipale } \\
\mathrm{s}\end{array}$ & $\begin{array}{c}\text { Situació } \\
\mathrm{n} \text { del } \\
\text { entorno }\end{array}$ & $\begin{array}{c}\text { Insta. } \\
\text { eléctricas }\end{array}$ & $\begin{array}{c}\text { Insta. } \\
\text { hidrosanit } \\
\text { arias }\end{array}$ & $\begin{array}{c}\text { Edad } \\
\text { del } \\
\text { inmuebl } \\
\text { e (años) }\end{array}$ & $\begin{array}{c}\text { Seguridad } \\
\text { (protecció } \\
\text { n civil) }\end{array}$ & $\begin{array}{c}\text { Medio } \\
\text { ambiente }\end{array}$ \\
\hline CDMX & 38.7 & 46.5 & 37.6 & 34.5 & 40 & 45.0 & 28.0 \\
\hline $\begin{array}{l}\text { EDO } \\
\text { MÉX }\end{array}$ & 34.3 & 34.7 & 37.5 & 38.1 & 37 & 44.1 & 20.5 \\
\hline HGO & 27.3 & 55.1 & 52.8 & 79.6 & 41 & 49.7 & 0.81 \\
\hline QRO & 29.4 & 20.2 & 21.9 & 25.0 & 50 & 20.1 & 40.5 \\
\hline MOR & 37.1 & 31.9 & 46.9 & 60.8 & 39 & 12.5 & 50.1 \\
\hline TLAX & 53.3 & 22.2 & 44.8 & 51.3 & 38 & 33.3 & 50.0 \\
\hline
\end{tabular}

Fuente: Elaboración propia

Los valores muestran una realidad preocupante, ya que se observó un valor máximo de cumplimiento en promedio de $53.3 \%$ solo en el estado de Tlaxcala referente a los servicios municipales básicos con los que una escuela necesita operar. Esta realidad repercute en los procesos escolares directamente y vulnera los derechos humanos debido a la precariedad de las condiciones en que el alumnado recibe su educación.

Asimismo, concerniente al resultado de la situación del entorno (medio geográfico) donde se encuentran los edificios evaluados, solo el estado de Hidalgo presenta en promedio como máximo un valor de $55.1 \%$ de cumplimiento. Al respecto, vale subrayar que este factor ambiental es de vital importancia para el desarrollo de la educación de los alumnos, ya que en el entorno de los planteles se encontró evidencia de zonas de riesgo o contaminación (p. ej., gasolineras, mercados, basureros, líneas de alta tensión, vías primarias rápidas y terminales de autobuses a menos de un kilómetro) (figura 6). 

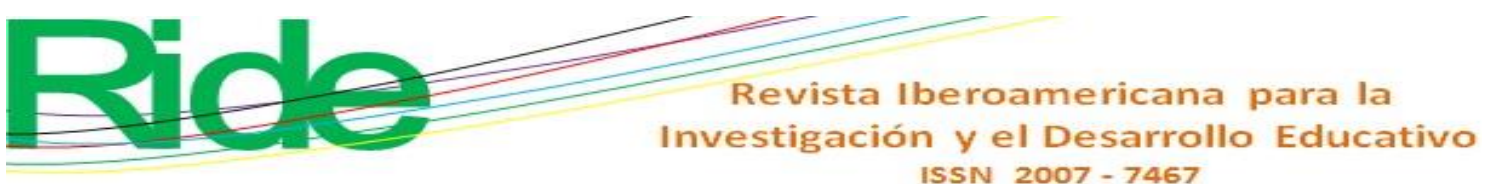

Figura 6. Planteles educativos que colindan en sus espacios exteriores con vías primarias sin protección ni señalización alguna (para los menores que transitan diariamente), así como con basureros a cielo abierto perjudiciales para la salud (transmisión de enfermedades infecciosas)
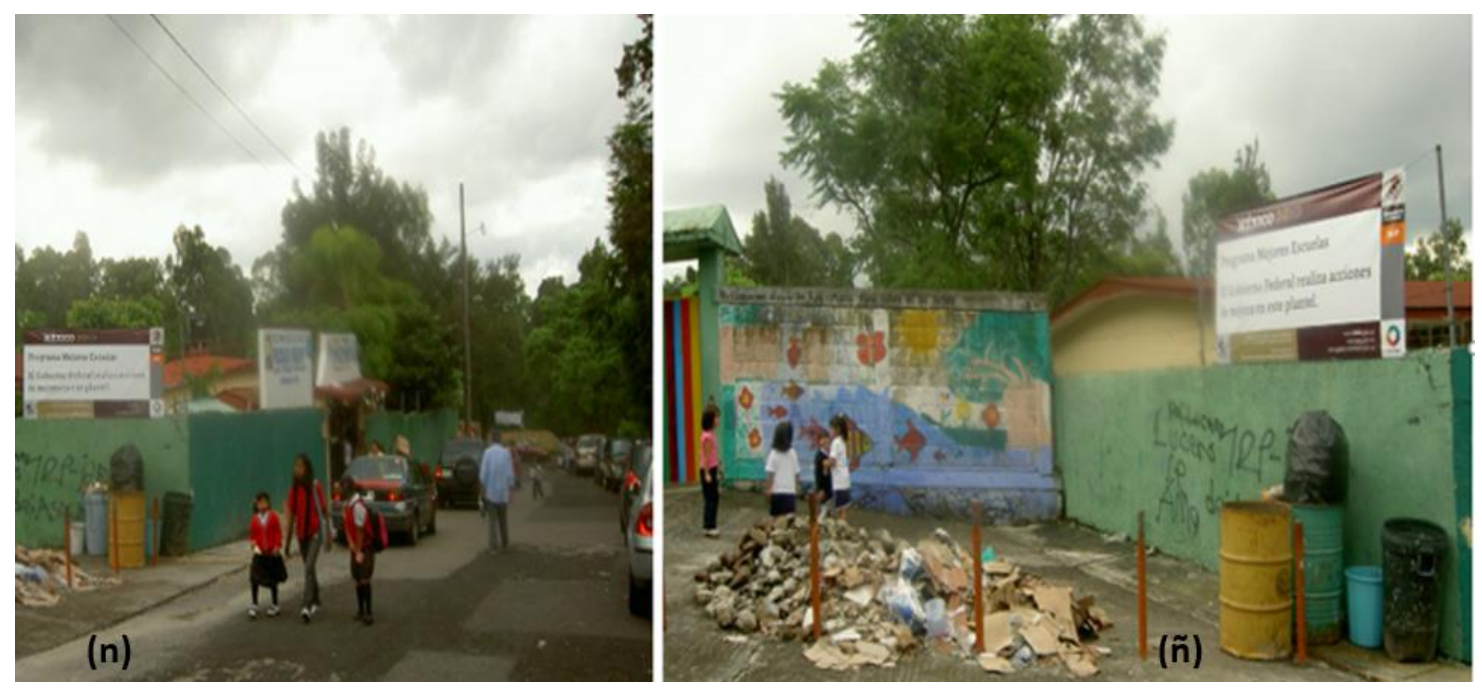

Fuente: Fotografía de Nancy Pacheco. (n) Estado de Tlaxcala, municipio de Apizaco

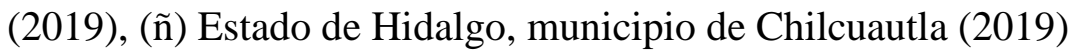

También se comprobó, referente a la seguridad y el medio ambiente, que en los planteles evaluados el valor más alto lo presentó en promedio el estado de Tlaxcala con 50 $\%$ (medio ambiente), mientras que en seguridad lo tuvo el estado de Hidalgo con $49.7 \%$. En síntesis, se puede afirmar que en los planteles se evidenciaron fallas en cuanto a barandales, dimensiones de escaleras y rampas, así como problemas en muros, techos y pisos por humedad, grietas, entre otros. De hecho, en la mayoría de las escuelas nunca se ha fumigado y en $11.5 \%$ de ellas nunca se ha llevado a cabo un mantenimiento profundo (figura 7). Asimismo, referente a las condiciones de las instalaciones tanto eléctricas como hidrosanitarias, solo el estado de Hidalgo presenta los valores más altos con $52.8 \%$ y 79.6 $\%$, respectivamente. 


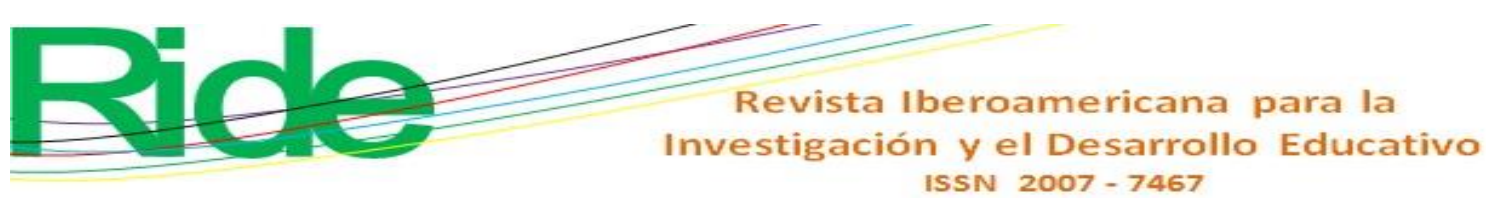

Figura 7. Áreas interiores de las casas adaptadas como planteles educativos que colindan con otras casas usadas como bodegas, cocinas, etc.
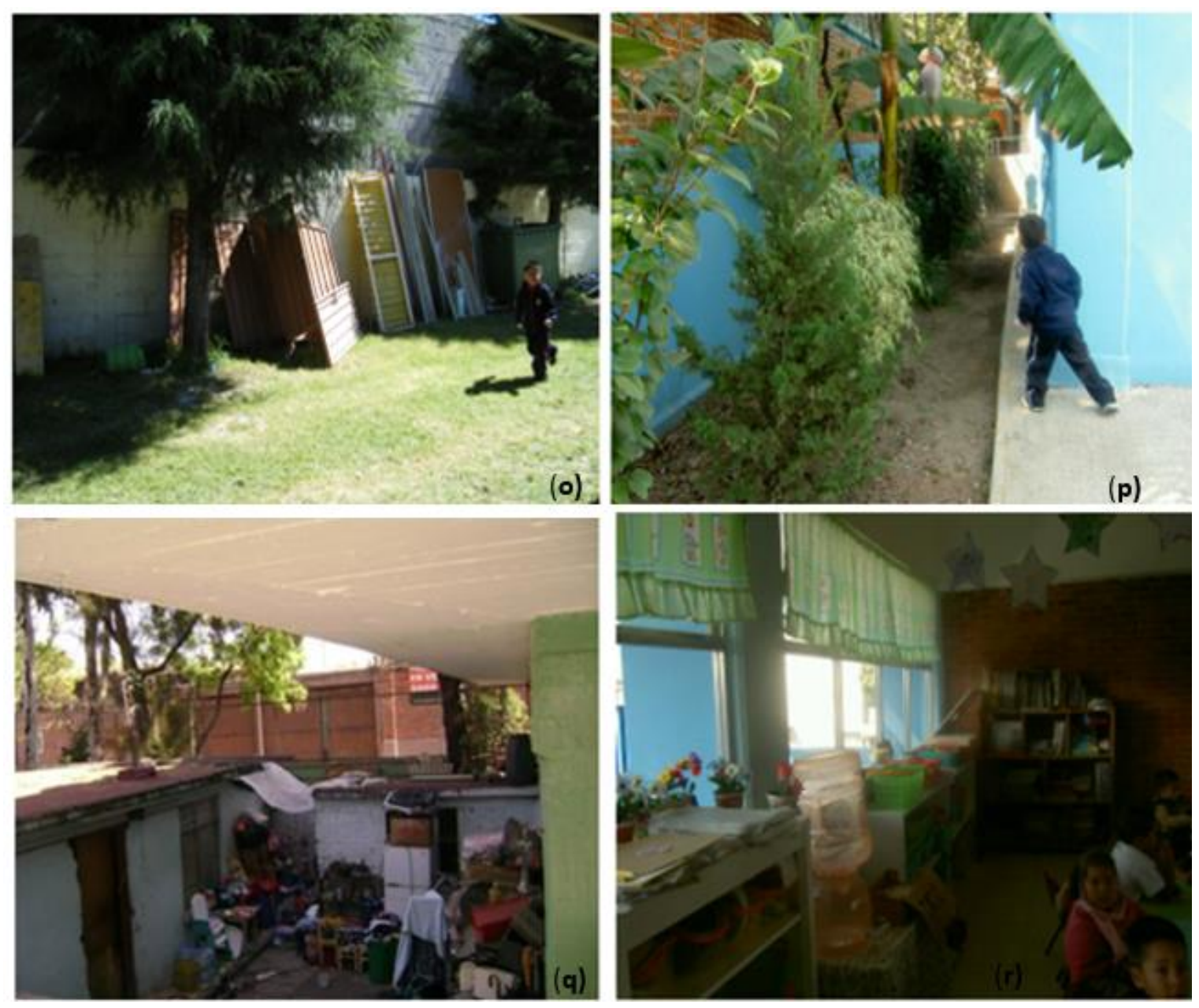

Fuente: Fotografía de Nancy Pacheco. (o) Estado de México, municipio de Atizapán Zaragoza (2019), (p) Ciudad de México, municipio Azcapotzalco (2019), (q) Estado de

Hidalgo, municipio de Lerma y (r) Estado de Querétaro, municipio de Huimilpan

En síntesis, se puede asegurar que los planteles evaluados presentan muchas deficiencias en materia de infraestructura, mobiliario y seguridad en general (figuras 8 y 9). 

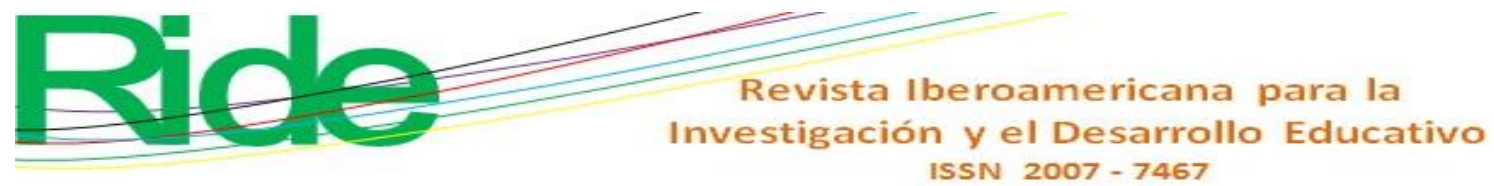
ISSN 2007- 7467

Figura 8. Instalaciones hidrosanitarias en mal estado y ambiente carente de higiene

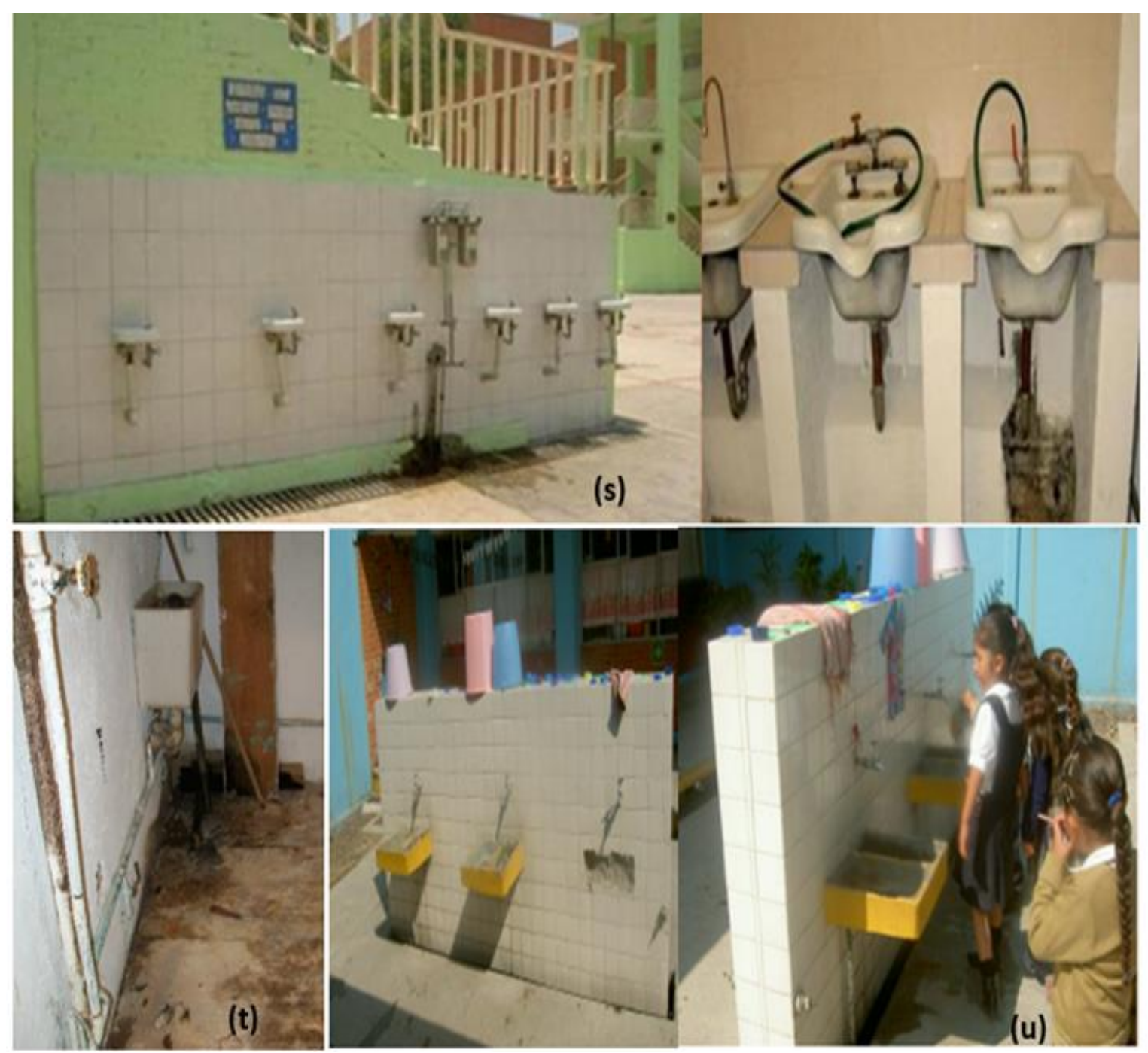

Fuente: Fotografía de Nancy Pacheco. (s) Estado de Querétaro, municipio de Tolimán (2019), (t) Ciudad de México, municipio Azcapotzalco (2019), (u) Estado de México, municipio de Coacalco de Berriozábal 

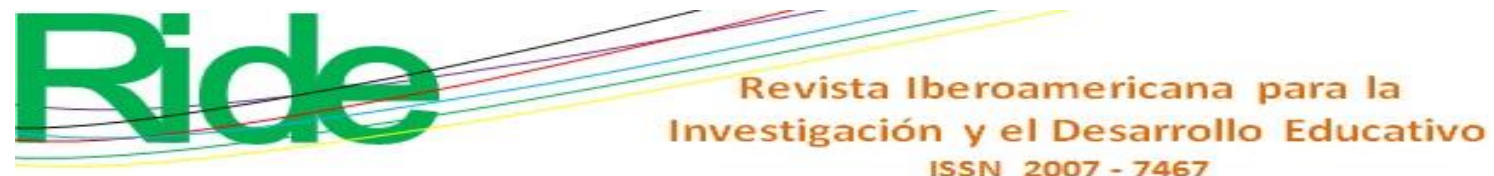
ISSN $2007-7467$

Figura 9. Nulo mantenimiento eléctrico en las instalaciones
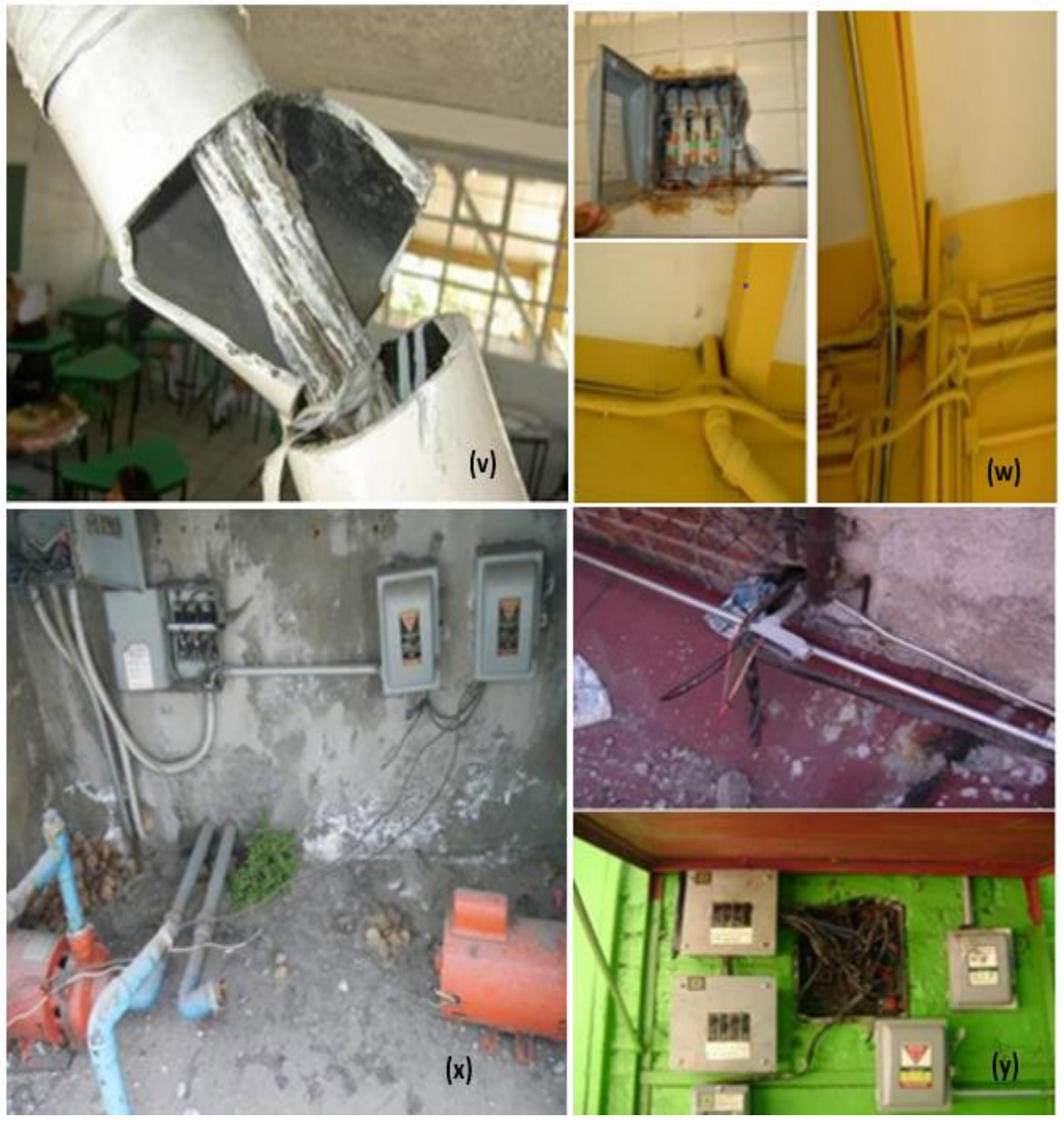

Fuente: Fotografía de Nancy Pacheco. (v) Estado de Querétaro, municipio de Huilmán (2019), (w) Ciudad de México, municipio Tláhuac (2019), (x) Estado de México, municipio de Acolman, (y) Estado de Tlaxcala municipio de Ixtenco 


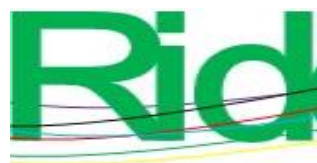

Revista Iberoamericana para la Investigación y el Desarrollo Educativo ISSN 2007 - 7467

\section{Discusión}

Sobre la primera interrogante plateada en este trabajo (¿qué relación existe entre la INFE y la educación que en su interior se imparte?), se puede indicar en el caso del nivel de preescolar la correcta distribución espacial proporciona una mejor organización de los materiales, así como un entorno físico rico en estímulos y posibilidades de acción. Asimismo, la relación entre el número de alumnos y profesores es muy importante en dicho nivel, puesto que los escolares exigen mayor atención y cuidado. Al respecto, cabe mencionar que para obtener la relación entre alumnos y maestros se utilizó la formulación de indicadores de la SEP, es decir, que la atención es la resultante de dividir la matrícula total de inicio de cursos entre el número total de maestros frente al grupo. Esto se puede calcular con la ecuación 1.

Relación alumno $/_{\text {maestro }}=\frac{\text { Matricula total }}{\text { Total de profesores existentes }} \ldots \ldots \ldots \ldots \ldots \ldots$................ $(1)$

La tabla 5 muestra los resultados de los valores del indicador relación de alumnos/maestros en la zona central de la República mexicana. 
Tabla 5. Indicador de relación alumno/maestro

\begin{tabular}{|c|c|c|c|c|}
\hline $\begin{array}{c}\text { Entidad } \\
\text { federativa }\end{array}$ & CCT & Alumnos & Maestro & $\begin{array}{l}\text { Indicador relación } \\
\text { alumno/maestro }\end{array}$ \\
\hline \multirow{3}{*}{ CDMX } & 09DJN04XX & 173 & 12 & 17 \\
\hline & 09DJN02XX & 80 & 9 & 11 \\
\hline & 09DJN01XX & 96 & 8 & 16 \\
\hline \multirow{3}{*}{ EDO MEX } & 9DJN014XX & 164 & 6 & 27 \\
\hline & 15EJN32XX & 436 & 18 & 27 \\
\hline & 15EJN41XX & 109 & 5 & 36 \\
\hline \multirow{3}{*}{ HGO } & 13DJN09XX & 173 & 14 & 14 \\
\hline & 09DJN07XX & 80 & 8 & 10 \\
\hline & 09DJN05XX & 183 & 13 & 14 \\
\hline \multirow{3}{*}{ QRO } & 22DJN01XX & 173 & 10 & 22 \\
\hline & 22DJN02XX & 48 & 3 & 16 \\
\hline & 22PJN006XX & 179 & 12 & 15 \\
\hline \multirow{3}{*}{ MOR } & 17DJN042XX & 95 & 7 & 19 \\
\hline & 17DJN006XX & 181 & 12 & 18 \\
\hline & 17DJN064XX & 72 & 4 & 36 \\
\hline \multirow{3}{*}{ TLAX } & 29EJN007XX & 40 & 5 & 13 \\
\hline & 29EJN001XX & 113 & 12 & 11 \\
\hline & 29DJN007XX & 129 & 9 & 18 \\
\hline \multicolumn{5}{|c|}{$\begin{array}{l}\text { NOTA: * Del total del personal que atiende a los alumnos, no se específica cuántos } \\
\text { son docentes, administrativos o personal de limpieza, ni cuántos están por horas ni } \\
\text { quiénes permanentemente. Por ello, el valor del indicador se realizó considerando que } \\
\text { el total del personal es docente menos dos personas: una administrativa y otra de } \\
\text { limpieza. } \\
\text { CCT: (clave de centro de trabajo): Es la llave de entrada al catálogo de centros de } \\
\text { trabajo (escuelas) autorizados por la SEP, así como el elemento de relación con todos } \\
\text { los sistemas de la SEP o de las autoridades educativas en los estados. } \\
\text { Entidad federativa o Estado: Unidad delimitada territorialmente que en unión de } \\
\text { otras entidades conforman a una nación. }\end{array}$} \\
\hline
\end{tabular}

Fuente: Elaboración propia

En las cifras anteriores se percibe una marcada diferencia entre el número de educandos y maestros. De hecho, las mayores magnitudes del indicador se registraron en el Estado de México y en el estado de Morelos. Igualmente, los resultados del análisis 


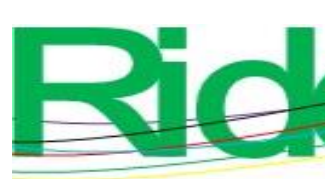

de

Revista Iberoamericana para la Investigación y el Desarrollo Educativo ISSN 2007 - 7467

estadístico demostraron que en el caso de la Ciudad de México ha existido la necesidad de mejorar y privilegiar una adecuada relación entre el número de alumnos por maestro, lo cual se ha venido reflejando a lo largo de las últimas décadas, según los censos desarrollados entre 1970 a 2017 por el Instituto Nacional de Estadística y Geografía (Inegi) (2013). En otras palabras, esa relación en el nivel de preescolar bajó de 38 a 21 alumnos por maestro en un lapso de 47 años (tabla 6).

Tabla 6. Relación alumnos-maestros (2018-2019)

\begin{tabular}{|l|c|c|}
\hline \multirow{2}{*}{ Entidad } & Preescolar & Primaria \\
\cline { 2 - 3 } & Núm. alumnos/maestro & $\begin{array}{c}\text { Núm. } \\
\text { alumnos/maestros }\end{array}$ \\
\hline $\begin{array}{l}\text { Ciudad de } \\
\text { México }\end{array}$ & 20 & 26 \\
\hline $\begin{array}{l}\text { Estado de } \\
\text { México }\end{array}$ & 22 & 27 \\
\hline Hidalgo & 19 & 21 \\
\hline Morelos & 21 & 25 \\
\hline Tlaxcala & 22 & 25 \\
\hline
\end{tabular}

Fuente: Elaboración propia con datos del INEGI (2013)

De los resultados presentados, resulta comprensible que se favorezca el contar con grupos reducidos, ya que en las secciones con más alumnos se suele invertir más tiempo en mantener la disciplina que en el desarrollo de las actividades de enseñanza y aprendizaje. Asimismo, se deben resaltar otras variables, como la preparación del maestro, la conducta de los alumnos en el grupo (según el nivel educativo) y la presencia de personal de apoyo (practicantes, prefectos, asistentes, etc.) para las asignaciones paralelas.

Igualmente, un aspecto que resulta interesante valorar en el contexto de este indicador es el de la infraestructura física de los planteles escolares y su uso como inmueble educativo porque constituye un elemento que puede condicionar los objetivos educativos planteados. Por ello, resulta imprescindible que la infraestructura física educativa (INFE) cumpla con determinada normatividad básica, aunque los hallazgos conseguidos en este trabajo contradicen este principio (ver las figuras 1,2 y 3 ). 


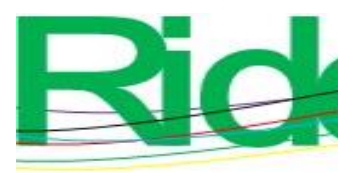

Revista Iberoamericana para la
Investigación y el Desarrollo Educativo
ISSN $2007-7467$

Por otra parte, y en cuanto al segundo cuestionamiento formulado (¿cuánto impacta el estado actual de la INFE en la eficacia de la educación?), los resultados enseñados en las tablas 2 y 3, así como en las figuras 4, 5, 6, 7, 8 y 9 revelan el impacto negativo que dichas condiciones pudieran estar generando en los 2524 alumnos que cursaban estudios en la instituciones de los seis estados de la región central de la República mexicana que constituyeron el corpus de la presente investigación. Lo anterior contradice algunos de los principios básicos del proceso de enseñanza-aprendizaje, los cuales se describen en seguida:

1. Impacto que recae en el docente y alumno

a) Dado que la INFE tiene un efecto motivacional en el proceso de aprendizaje, al contar con un ambiente adecuado y agradable, los alumnos y docentes tienen un mejor desempeño.

b) El profesor debe procurar que el estudiante aprenda en circunstancias que lo acerquen a su realidad, en el marco de su propia cultura. Por ello, es imprescindible informar a las autoridades de las condiciones en las cuales se encuentra la INFE para asegurar la integridad y salud de los alumnos, los docentes y las personas que laboran en ella.

c) La ausencia de profesores (o el no contar con el número mínimo de ellos) se traduce en atrasos en el aprendizaje y en un menor rendimiento académico.

2. Manifestación del lenguaje oral

a) El estrés, el agotamiento y las patologías de la voz y la vista son algunos problemas que padecen con mayor frecuencia los docentes como consecuencia del ruido, la deficiente iluminación y la inadecuada ventilación de la INFE, lo que repercute directamente en el aprendizaje de los alumnos.

b) El ruido perjudica el rendimiento escolar de los alumnos porque dificulta sus procesos de atención y aprendizaje.

c) La estabilidad emocional se puede ver afectada por la inseguridad del entorno, el medio ambiente, el mobiliario usado y las instalaciones en general.

3. Escuchar y expresarse

a) El entorno inseguro puede afectar la creatividad del alumno, así como sus medios de expresión artística y cultural.

\section{Pensamiento matemático}

a) Los procesos de desarrollo y las experiencias vividas se pueden ver afectados por un medio ambiente insalubre e inseguro. 

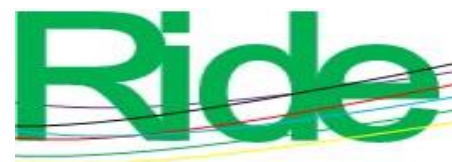

Revista Iberoamericana para la Investigación y el Desarrollo Educativo

ISSN $2007-7467$

b) El mobiliario, los equipos y las instalaciones fuera de norma pueden afectar el desarrollo de actividades donde se deban reconocer objetos de diversos tamaños.

c) Sus juicios pueden ser genuinamente cuantitativos y expresados de diversas maneras en situaciones cotidianas, aunque mermados por los recursos con los que cuentan (instalaciones insalubres, carencia de mobiliario, etc.).

5. Conservación del medio ambiente

a) La carencia de agua y luz, así como los inmuebles insalubres y fuera de la norma puede perjudicar la concepción de los alumnos en cuanto al cuidado de plantas y animales de su entorno.

b) Un entorno dañino e inseguro puede inculcar los efectos desfavorables de la acción humana sobre el ambiente.

6. Comunica las sensaciones y los sentimientos que le producen los sonidos de su entorno y lo que escucha

a) Al estar rodeado de espacios de doble uso (bodegas, cocinas, gasolineras, etc.), el alumno se puede habituar a un ambiente que no tiene relación con un espacio diseñado para la enseñanza y aprendizaje.

Finalmente, para dar respuesta a la tercera pregunta planteada (¿qué papel desempeña el cumplimiento normativo de INFE en dicha relación de impacto en la educación?), se demostró que el nexo entre la INFE y la educación trasciende sus paredes, pues también implica toda su estructura, la cual influye en el rendimiento del alumno. Al respecto, la normatividad es de vital importancia para ordenar la convivencia y guiar los comportamientos de todos los individuos. La tabla 7 evidencia el grado de cumplimiento normativo recabado de este estudio y cómo esto afecta el aprendizaje de los educandos. 


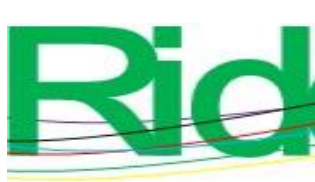

Revista Iberoamericana para la Investigación y el Desarrollo Educativo ISSN 2007 - 7467

Tabla 7. Marco normativo de la INFE

\begin{tabular}{|c|c|c|}
\hline Docum & $\begin{array}{l}\text { Artículos o } \\
\text { numerales }\end{array}$ & Cumplimiento \\
\hline $\begin{array}{l}\text { Constitución } \\
\text { Política de los } \\
\text { Estados } \\
\text { Unidos } \\
\text { Mexicanos. }\end{array}$ & Artículo 3, párrafo 3 & $\begin{array}{l}\text { El derecho se ve mermado, ya que las evidencias } \\
\text { encontradas demuestran falta de responsabilidad } \\
\text { del Estado. }\end{array}$ \\
\hline $\begin{array}{l}\text { Ley General } \\
\text { de Educación }\end{array}$ & Artículo 1 y 2 & $\begin{array}{l}\text { Se comprobó carencia de su cumplimiento, lo } \\
\text { cual repercute en el aprendizaje de los } \\
\text { estudiantes. En la norma se establece que se debe } \\
\text { "recibir educación de calidad en condiciones de } \\
\text { equidad". }\end{array}$ \\
\hline $\begin{array}{l}\text { Ley General } \\
\text { de la } \\
\text { Infraestructura } \\
\text { Física } \\
\text { Educativa }\end{array}$ & Del Artículo 1 al 33 & $\begin{array}{l}\text { Falta de lineamientos generales de construcción, } \\
\text { equipamiento, mantenimiento, rehabilitación, } \\
\text { reforzamiento, reconstrucción y habilitación de } \\
\text { inmuebles e instalaciones destinados al servicio } \\
\text { del sistema educativo nacional. }\end{array}$ \\
\hline $\begin{array}{l}\text { Reglamentos } \\
\text { de } \\
\text { construcción } \\
\text { por estados }\end{array}$ & $\begin{array}{l}\text { Articulo } \\
\text { (CDMX). } \\
\text { Artículos 87, } 332, \\
\text { 334, } 613 \text { (Tlaxcala). } \\
\text { Artículo } \\
\text { (Puebla). } \\
\text { Artículo } \\
\text { (Querétaro). } \\
\text { Artículo } \\
\text { (Morelos) } \\
\text { Artículo 88 (Estado } \\
\text { de Morelos). }\end{array}$ & $\begin{array}{l}\text { La superficie del terreno deberá estar en relación } \\
\text { con el número de alumnos para el que esté } \\
\text { destinado el edificio. No pueden ser menos de } 5 \\
\text { metros cuadrados por alumno (escaso } \\
\text { cumplimiento). } \\
\text { Las escuelas públicas o privadas y cualquier otra } \\
\text { edificación destinada a la enseñanza deberán } \\
\text { contar con el visto bueno de seguridad y } \\
\text { operación de un director responsable de obra, lo } \\
\text { cual nunca se demostró con evidencia. } \\
\text { Falta de local de enfermería y/o consultorio } \\
\text { médico. Cada escuela debe contar con un local } \\
\text { adecuado para enfermería y equipo de } \\
\text { emergencia, así como de rampas en todo }\end{array}$ \\
\hline
\end{tabular}




\begin{tabular}{|c|c|c|}
\hline & & $\begin{array}{l}\text { Revista lberoamericana para la } \\
\text { nvestigación y el Desarrollo Educativo } \\
\text { issN } 2007-7467\end{array}$ \\
\hline & & $\begin{array}{l}\text { desnivel y pasamanos de apoyo en escaleras para } \\
\text { alumnos con discapacidad (nula evidencia de } \\
\text { ello). } \\
\text { Las áreas exteriores de juegos en escuelas de } \\
\text { nivel inicial se situarán próximas a sus aulas e } \\
\text { incorporarán fosos de arena y zonas } \\
\text { pavimentadas (insuficiencia de cumplimiento } \\
\text { para casas adaptadas). } \\
\text { Equipo de áreas de juego: Columpios, } \\
\text { toboganes, carruseles, balancines (equipos } \\
\text { basculantes), revestimiento de las superficies de } \\
\text { áreas de juego absorbentes de impacto (nulo } \\
\text { cumplimiento). } \\
\text { Los espacios deben ser los adecuados según los } \\
\text { requerimientos pedagógicos y ofrecer el máximo } \\
\text { de posibilidades de adaptación y flexibilidad al } \\
\text { uso del mobiliario, equipo y material educativo } \\
\text { necesarios para su desarrollo } \\
\text { cumplimiento). }\end{array}$ \\
\hline $\begin{array}{l}\text { Programas de } \\
\text { protección } \\
\text { civil }\end{array}$ & & $\begin{array}{l}\text { Se debe contar con un plan de protección civil, } \\
\text { alarma sísmica de prevención, cantidad de } \\
\text { extintores existentes, cantidad de botiquines de } \\
\text { primeros auxilios existentes (con suministros } \\
\text { vigentes), señalamientos de prevención, } \\
\text { señalamientos de rutas de evacuación, } \\
\text { señalamientos de puntos de reunión (insuficiente } \\
\text { desempeño). }\end{array}$ \\
\hline Documento & $\begin{array}{l}\text { Artículos o } \\
\text { numerales }\end{array}$ & Cumplimiento \\
\hline $\begin{array}{l}\text { Normas NOM } \\
\text { y NMX }\end{array}$ & $\begin{array}{l}\text { Artículos 220- } \\
86 \text { (instalaciones } \\
\text { eléctricas). }\end{array}$ & $\begin{array}{l}\text { Accesibilidad. Tanto en zona rural como en zona } \\
\text { urbana, el acceso principal al predio y a la } \\
\text { escuela debe realizarse a través de vialidades }\end{array}$ \\
\hline
\end{tabular}




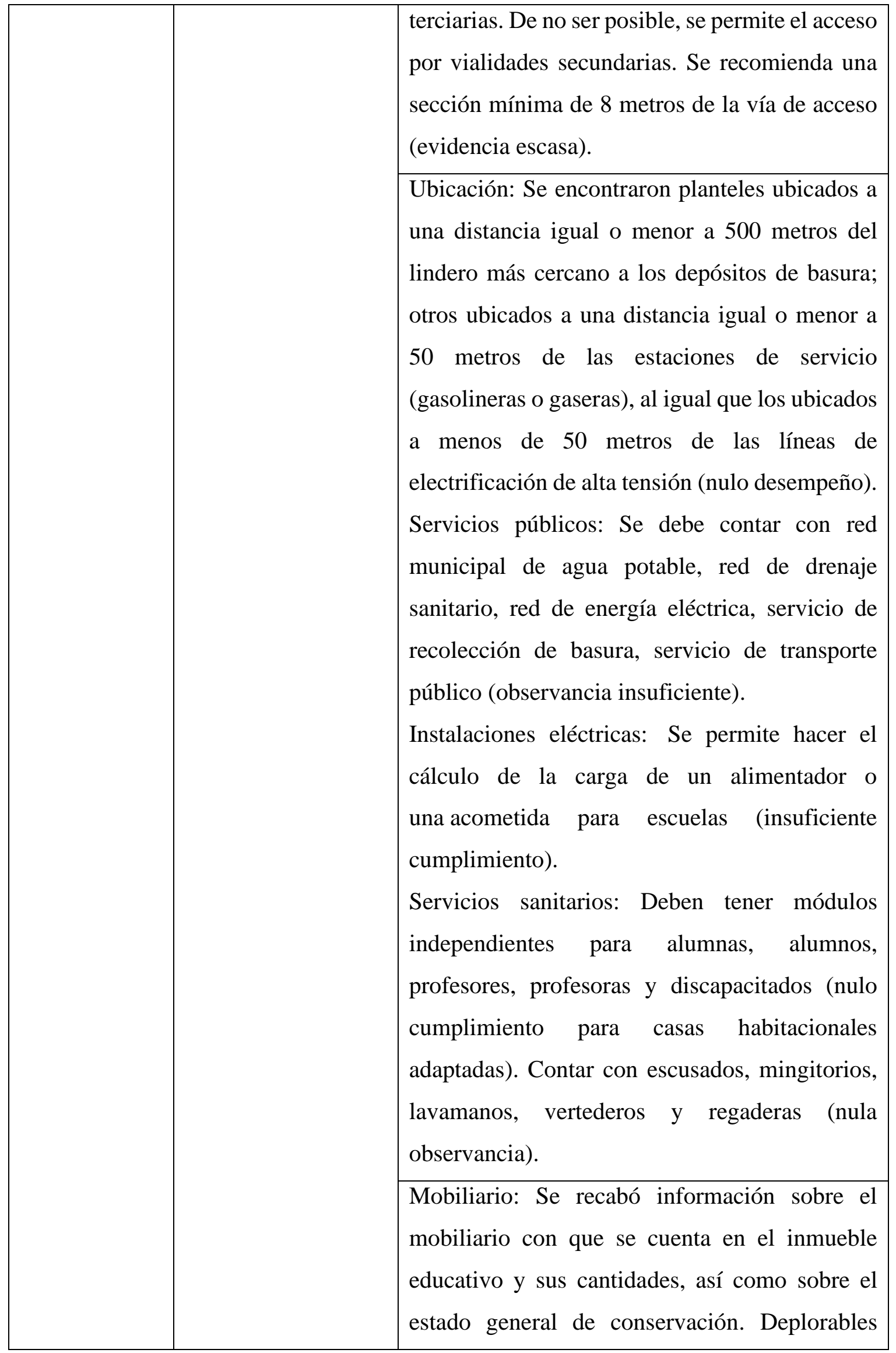




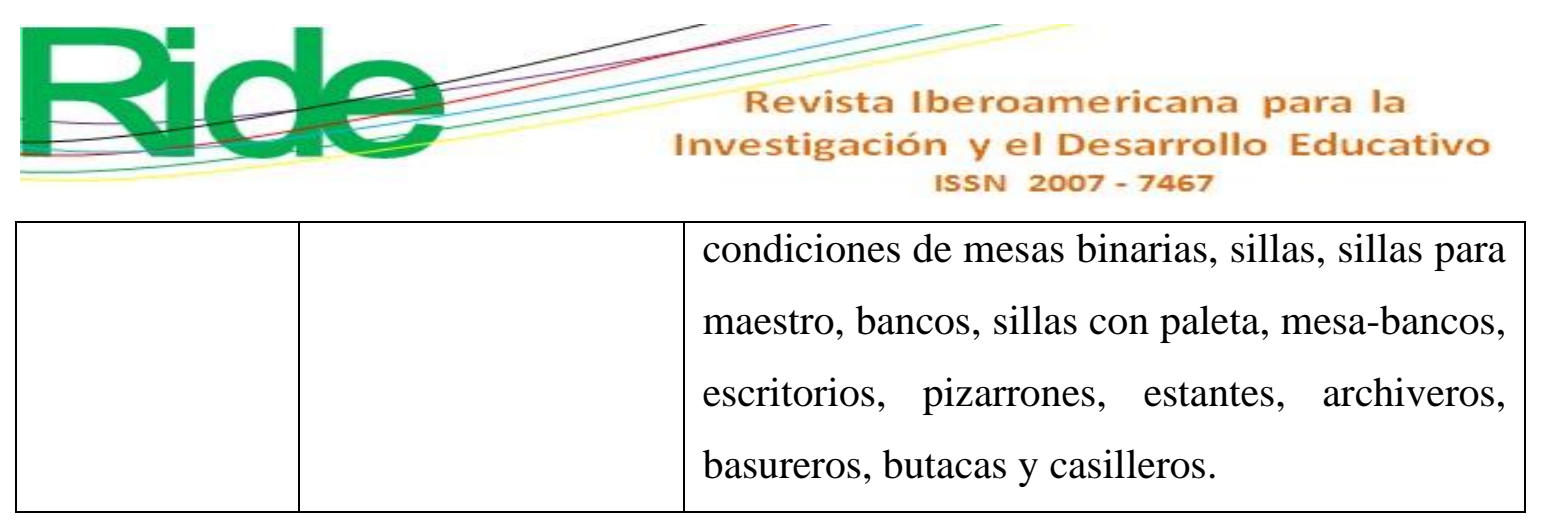

Fuente: Elaboración propia

Como se puede apreciar, las condiciones encontradas en los inmuebles evaluados exponen múltiples deficiencias, lo que repercute directamente en el aprendizaje de los educandos.

\section{Conclusiones}

Los hallazgos mostrados en la presente investigación evidencian la carencia del cumplimiento normativo básico en las instituciones analizadas del nivel de preescolar, lo que afecta el desarrollo integral y armónico del niño. En concreto, al estudiar las relaciones entre infraestructura escolar y resultados obtenidos se observa que los factores que están más alta y significativamente asociados con los aprendizajes son su uso como espacio educativo (planeación), la presencia de espacios de apoyo a la docencia (bibliotecas y áreas comunes), la conexión a servicios públicos de electricidad, agua potable, mobiliario y equipo adecuados, así como baños en condiciones y con número apropiado.

Esto demuestra que los estados de la región central de la República mexicana deberán mejorar la infraestructura física educativa para eliminar las grandes brechas existentes, las cuales impactan negativamente en las escuelas del sector público. En tal sentido, se deberá invertir en la construcción de edificios que cumplan con los requisitos mínimos para impartir clases según las particularidades de cada nivel educativo. Esto significa trabajar en la mejora y mantenimiento de las instalaciones hidráulicas, sanitarias y eléctricas.

Finalmente, se deben crear iniciativas que permitan optimizar los instrumentos que orientan las políticas públicas en el campo de infraestructura física educativa. Para ello, será indispensable promover más estudios tanto a nivel comparativo regional como internacional para robustecer el análisis de las conexiones entre la infraestructura escolar y los aprendizajes de los estudiantes. 


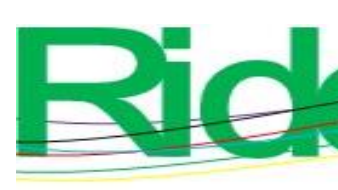

Revista Iberoamericana para la
Investigación y el Desarrollo Educativo
ISSN $2007-7467$

Futuras líneas de investigación

Es conveniente continuar profundizando para consolidar esta línea de investigación, lo cual se podría conseguir si se desarrollan indagaciones en escuelas privadas y se amplía la muestra incluyendo a otras regiones de la República mexicana y a otros niveles educativos.

\section{Referencias}

Blincoe, J. M. (2005). The age and condition of Texas high schools as related to student academic achievement. University of Texas. Retrieved from https://repositories.lib.utexas.edu/bitstream/handle/2152/18052/blincoej72948.pdf?s equence $=2 \&$ is Allowed $=\mathrm{y}$

Boese, S. and Shaw, J. (2*/9005). New York state school facilities and student health, achievement and attendance: A data analysis report. Healthy Schools Network. Retrieved from https://files.eric.ed.gov/fulltext/ED510053.pdf

Branham, D. (2004). The wise man builds his house upon the rock: The effects of inadequate school building infrastructure on student attendance. Social Science Quarterl, 85(5). Retrieved from https://onlinelibrary.wiley.com/doi/abs/10.1111/j.00384941.2004.00266.X

Bullock, C. C. (2007). The relationship between school building conditions and student achievement at the middle school level in the commonwealth of Virginia. Virginia Polytechnic Institute and State University. Retrieved from https://vtechworks.lib.vt.edu/bitstream/handle/10919/28749/calvinbullock.pdf?sequ ence $=2 \&$ is Allowed $=\mathrm{y}$

Campana, Y., Velasco, D., Aguirre, J. y Guerrero, E. (2014). Inversión en infraestructura educativa: una aproximación a la medición de sus impactos a partir de la experiencia de los colegios emblemáticos (informe final). Lima: Consorcio de Investigación Económica y Social. Recuperado de https://cies.org.pe/sites/default/files/investigaciones/20141002_informe_final_coleg ios_emblematicos_corregido.pdf

Constitución Política de los Estados Unidos Mexicanos [CPEUM] (2017). Recuperado de http://www.diputados.gob.mx/LeyesBiblio/pdf_mov/Constitucion_Politica.pdf

Diario Oficial de la Federación [DOF] (30 de septiembre de 2019). Ley General de Educación [LGE]. México. D.F. Recuperado de https://dof.gob.mx/nota_detalle.php?codigo=5573858\&fecha=30/09/2019 


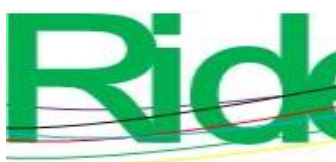

Revista Iberoamericana para la
Investigación y el Desarrollo Educativo
ISSN $2007-7467$

Diario Oficial de la Federación [DOF] (4 de abril de 2019). ACUERDO por el que se emiten los lineamientos específicos de operación del Programa Nacional de Reconstrucción en el Sector Educativo para el ejercicio fiscal 2019. México. D. F. Recuperado de http://www.reconstruyendoesperanza.gob.mx/difusion/wpcontent/uploads/2019/09/Lineamientos-Especificos_INIFED-2019.pdf

Duarte, J., Gargiulo, C. y Moreno, M. (2011). Infraestructura escolar y aprendizajes en la educación básica latinoamericana: un análisis a partir del SERCE. BID. Recuperado de https://publications.iadb.org/es/infraestructura-escolar-yaprendizajes-en-la-educacion-basica-latinoamericana-un-analisis-partir

Durón, T. L. y Oropeza, T. R. (1999). Actividades de estudio: análisis predictivo a partir de la interacción familiar y escolar de estudiantes de nivel superior. Facultad de Psicología, Universidad Nacional Autónoma de México.

Higgins, S., Hall, E., Wall, K., Woolner, P. and McCaughey, C. (2005). The Impact of School Environments: A literature review. Callaghan, NSW: University of Newcastle.

Instituto de la Infraestructura Física Educativa [INIFED] (2014). Normas y especificaciones para estudios, proyectos, construcción e instalaciones. Instituto de la Infraestructura Física Educativa. Recuperado de https://www.gob.mx/cms/uploads/attachment/file/89279/Tomo2_Accesibilidad.pdf

Instituto de la Infraestructura Física Educativa [INIFED] (2019). Anexo 1. Formato de información técnica para la evaluación para la certificación de la calidad de la INFE 2019. Instituto de la Infraestructura Física Educativa. Recuperado de https://www.gob.mx/inifed/documentos/anexo-1-formato-de-informacion-tecnicapara-la-evaluacion-para-la-certificacion-de-la-calidad-de-la-infe-2019

Instituto Nacional de Estadística y Geografía [Inegi] (2013). Censo de escuelas, maestros y alumnos de educación básica y especial 2013. Atlas educativo. Inegi. Recuperado de https://www.inegi.org.mx/sistemas/mapa/atlas/

Instituto Nacional para la Evaluación de la Educación [INEE] (2018). Marco de referencia para la evaluación de condiciones básicas para la enseñanza y el aprendizaje (documento interno del INEE). Instituto Nacional para la Evaluación de la Educación. Recuperado de https://www.inee.edu.mx/wpcontent/uploads/2018/12/P1E205.pdf

Jadille, B. (20016). Tarea pública: escuelas para Chile. MINEDUC. Diseño para la educación del siglo XXI. Cuatro miradas sobre diseño y educación. Recuperado de 

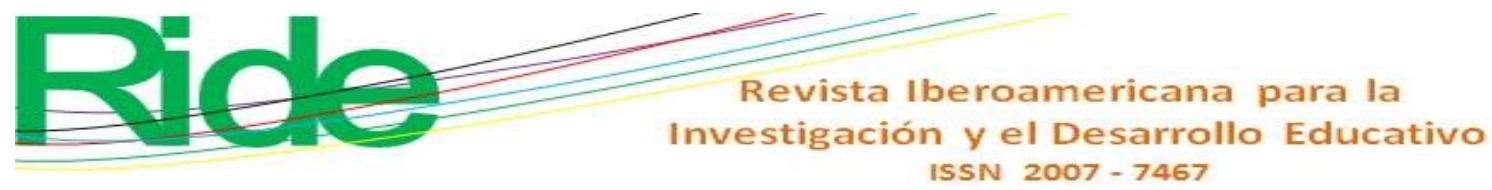

https://repositorio.udd.cl/bitstream/handle/11447/1441/03\%20Baza\%2C\%20J.pdf?s equence $=1 \&$ is Allowed $=\mathrm{y}$

Jenkins, J. and Oatley, K. (1998). The Development of Emotion. Schemas in Children. In Flack, W. and Laird, J. Emotions in psychopathology (pp. 45-56). Oxford University Press. New York.

Ley General de la Infraestructura Física Educativa [LGINFE] (2008). Recuperado de https://www.sep.gob.mx/work/models/sep1/Resource/31 ee49a5-10f4-4264-9cb4730691f53d0f/ley_general_infra_fisica_educativa.pdf

Mahoney, M. (1997). Emotionality and Health: Lessons from and for Psychotherapy. In Pennebaker, J. W. (ed.), Emotion, disclosure, \& health (p. 241-253). American Psychological Association. Retrieved from https://psycnet.apa.org/record/199598769-011

Norma Mexicana (2011). NMX-R-003-SCFI-2011. Escuelas —selección del terreno para construcción - requisitos (cancela a la NMX-R-003-SCFI-2004). Recuperado de https://www.gob.mx/cms/uploads/attachment/file/104884/NMX-R-

003_Escuelas_Seleccion_del_terreno.pdf

Norma Mexicana (2013). NMX-R-021-SCFI-2013 Escuelas — calidad de la infraestructura física educativa- requisitos. Recuperado de https://www.gob.mx/cms/uploads/attachment/file/104914/NMX-R021_Calidad_de_la_INFE_requisitos.pdf

Norma Mexicana (2015a). NMX-R-084-SCFI-2015 Escuelas -levantamiento de datos para el diagnóstico de la infraestructura física educativa- directrices y requisitos. Recuperado de https://www.gob.mx/cms/uploads/attachment/file/280292/NMX-R084-SCFI-2015-.pdf

Norma Mexicana (2015b). NMX-R-024-SCFI-2015. Escuelas — supervisión de obra de la infraestructura física educativa- requisitos. Recuperado de https://www.gob.mx/cms/uploads/attachment/file/104638/NMX-R-024-SCFI2015.pdf

Norma Mexicana (2015c). NMX-R-079-SCFI-2015 Escuelas —seguridad estructural de la infraestructura física educativa- requisitos. Recuperado de https://www.gob.mx/cms/uploads/attachment/file/104639/nmx-r-079-scfi-2015.pdf 


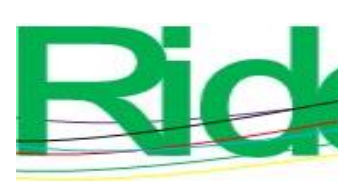

Revista Iberoamericana para la
Investigación y el Desarrollo Educativo
ISSN $2007-7467$

Norma Mexicana (2015d). NMX-R-080-SCFI-2015 Escuelas -bebederos de agua potable- requisitos. Recuperado de https://www.gob.mx/cms/uploads/attachment/file/104640/nmx-r-080-scfi-2015.pdf

Norma Mexicana (2016). NMX-R-090-SCFI-2016. Escuelas -elementos para la accesibilidad a los espacios de la infraestructura física educativa- requisitos. Recuperado de https:/www.gob.mx/cms/uploads/attachment/file/453015/NMX-R090-SCFI-2016.pdf

Norma Mexicana (2019). NMX-R-083-SCFI-2019. Escuelas -diseño y fabricación de mobiliario para la infraestructura física educativa- criterios y requisitos. Recuperado de http://www.inifed.gob.mx/doc/pdf/2019/NMX\%20R\%20083\%20SCFI\%202015\%2 0ESCUELAS\%20DISE\%C3\%910\%20Y\%20FABRICACION\%20DE\%20MOBIL IARIO\%20PARA\%20LA\%20INFRAESTRUCTURA\%20FISICA\%20EDUCATI VA\%20CRITERIOS\%20Y\%20REQUISITOS.pdf

Organización de las Naciones Unidas para la Educación, la Ciencia y la Cultura [Unesco] (2016). La educación al servicio de los pueblos y el planeta: creación de futuro sostenible para todos. Recuperado de https://www.gcedclearinghouse.org/sites/default/files/resources/248526s.pdf

Picus, L. O., Marion, S. F., Calvo, N. and Glenn, W. J. (2005). Understanding the relationship between student achievement and the quality of educational facilities: Evidence from Wyoming. Peabody Journal of Education, 80(3), 71-95. Retrieved from https://www.tandfonline.com/doi/abs/10.1207/s15327930pje8003_5

Secretaría de Educación Pública [SEP] (2008). Glosario. Términos utilizados en la Dirección General de Planeación y Programación 2008. Recuperado de http://cumplimientopef.sep.gob.mx/2010/Glosario\%202008\%2024-jun-08.pdf

Secretaría de Educación Pública [SEP] (2019). Lineamientos para la formulación de indicadores. Secretaría de Educación Pública. Recuperado de https://www.planeacion.sep.gob.mx/Doc/estadistica_e_indicadores/lineamientos_fo rmulacion_de_indicadores.pdf 


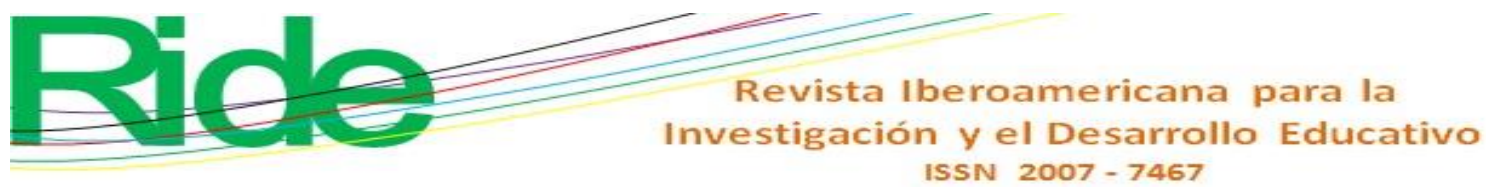

Segundo Estudio Regional Comparativo y Explicativo [SERCE] (2008). Los aprendizajes de los estudiantes de América Latina y el Caribe: reporte técnico. Unesco. Recuperado de https://unesdoc.unesco.org/ark:/48223/pf0000190297 